\title{
Impact of Educational Program on The Level of Knowledge and Self-Care Behaviors towards Genitourinary Tract Infection among Female Adolescent Students In Zagazig City
}

\author{
${ }^{1}$ Hanaa A. Nofal, ${ }^{2}$ Noha M. Hammad, ${ }^{3}$ Amany M. Abdallah and ${ }^{1}$ Hala A. Magdy ${ }^{\mathrm{a}}$ \\ ${ }^{1}$ Public Health and Preventive Medicine department, ${ }^{2}$ Medical Microbiology and \\ Immunology Department, ${ }^{3}$ Family Medicine Faculty of Medicine, Zagazig University, \\ Zagazig, Egypt.
}

\begin{abstract}
Background: Genitourinary tract infections (GUTI) are serious health problems affecting millions of people each year, especially female adolescents. This is might be due to hormonal changes that favor vaginal colonization and together with decreased knowledge about genital hygiene during this period of life. Objective: The aim of this study was to evaluate a prevention program on knowledge and habitual practices regarding prevention of urinary tract infection among female adolescents. Method: A quasi experimental design was conducted in three preparatory and one secondary school for girls in Zagazig city. 770 female students in age group (12 -16 year) were randomly selected. Data were collected using an interview questionnaire covering socio-demographic data. Urine samples were collected to estimate the prevalence of urinary tract infections and to detect antibiotic susceptibility pattern. Assessment of knowledge related to GUTI and habitual practices of personal hygiene was done via pre and post-test Results: There was an improvement in knowledge related to prevention of genitourinary infection and to habitual practices among female adolescents regarding personal hygiene related to prevention of GUTI. Conclusion: To increase the success of the education, teachers and health officials must collaborate with parents and other family members.
\end{abstract}

Keywords: adolescents, genitourinary tract infection, health education.

Corrosponding author: Amany Mohammed AbdAllah E.mail: dr.amanymohammed@gmail.com

\section{Introduction}

World health organization (WHO) defines adolescence as the period in human growth and development that occurs after childhood and before adulthood, from ages 10 to 19 years. ${ }^{1}$

Genitourinary tract infection (GUTI) is very common among females in all age groups. During adolescence hormonal changes favor vaginal colonization by nephritogenic strains of bacteria, which can migrate to the periurethral area and cause UTI. It is associated with poor selfesteem, impaired quality of life. Many factors like low water intake, infrequent voiding and poor menstrual hygiene have been implicated in UTI during adolescence $^{2}$ Changizi $^{3}$ found that the main factor predisposing to genitourinary tract infection(GUTI) has been attributed to poor personal hygiene and culture habits.

Infection of the urinary tract could manifest differently depending on the site of the infection and length of time involved. Infections that affect the lower urinary tract are called the cystitis, involving the bladder alone with symptoms including painful urination, burning sensation, either frequency or urge to urinate (or both), while those that affect upper urinary tract are called the pyelonephritis, involving the kidney. The symptoms of the upper urinary tract include; fever and flank pain during 
urination in addition to those of the lower urinary tract. ${ }^{4}$

Adolescent females have the most common medical complains of GUTI. It is estimated that $25 \%$ of girls visited health care clinic each year due to lack of adequate knowledge and hygienic practices, and poor hygiene school toilets. ${ }^{5}$ Escherichia coli (E. coli), that lives on the skin near the anus or vagina, can spread and enter the urinary tract through the urethra and bacteria can enter the urinary tract when women wipe from back to front after using the bathroom. ${ }^{6}$ Health education about healthy behaviors can affect their susceptibility to the disease. GUT can be prevented by appropriate healthy behaviors. Schools and all public places should have basic and clean sanitation facilities. Few reports were done on this subject before.

This study aimed to improve the level of knowledge and self-care behaviors towards GUTI among female adolescents students in Zagazig city through detection of prevalence of UTIs among female adolescent students and decrease the prevalence of UTI,to assess students' knowledge and habitual practices regarding the prevention of GUTI among school age students and to evaluate the effect of prevention program regarding the students practices for prevention of GUTI.

\section{Method}

Research design and setting: A quasiexperimental study. This study was conducted at three preparatory females' schools in Zagazig city, (namely Elnasriya preparatory school, preparatory females' school and preparatory English school) and one secondary school (namely; Gamal Abd Elnaser secondary school).

Study sample:

Two phases: $1^{\text {st }}$ phase selection of sample to assess genitourinary tract infection by assuming prevalence of UTI as $65 \%$ Ojo and Anibijuwon ${ }^{(7)}$ at at $95 \%$ confidence

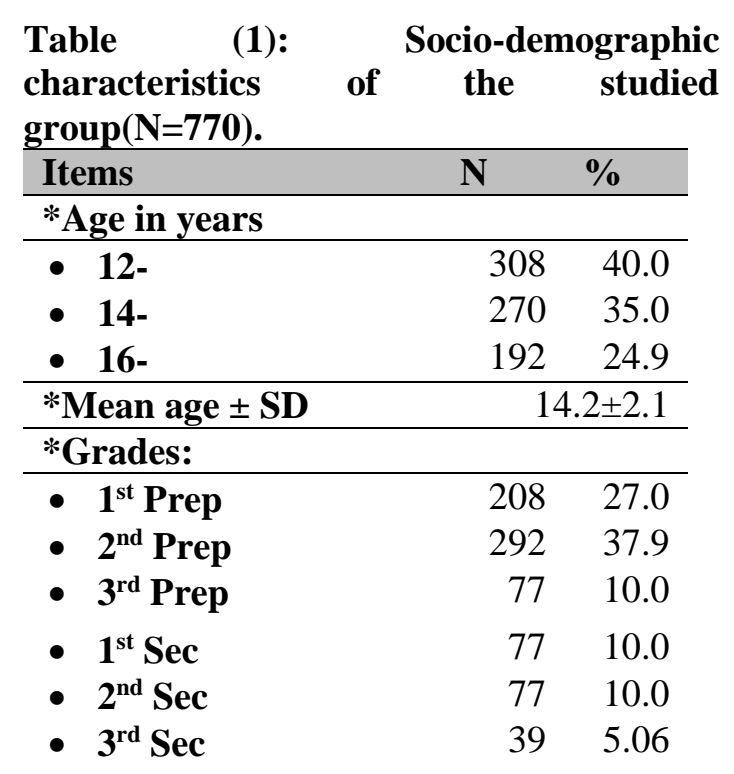

\begin{tabular}{lll}
\hline *Mother education & & \\
\hline - Basic & $\mathbf{2 0 8}$ & $\mathbf{2 7 . 0}$ \\
- Intermediate & $\mathbf{2 7 0}$ & $\mathbf{3 5 . 0}$ \\
- High education & $\mathbf{2 9 2}$ & $\mathbf{3 7 . 9}$ \\
\hline *Mother Job & & \\
\hline $\begin{array}{l}\text { - House wife } \\
\text { - Working }\end{array}$ & $\mathbf{5 8 5}$ & $\mathbf{7 6 . 0}$ \\
\hline *Family monthly & & \\
income & & \\
\hline $\begin{array}{l}\text { - Not enough } \\
\text { - Enough }\end{array}$ & $\mathbf{1 5 4}$ & $\mathbf{2 0 . 0}$ \\
- Enough and saving & $\mathbf{8 6}$ & $\mathbf{1 1 . 2}$ \\
\hline *Housing condition & & \\
\hline - Sanitary & $\mathbf{6 0 2}$ & $\mathbf{7 8 . 2}$ \\
- Non sanitary & $\mathbf{1 6 8}$ & $\mathbf{2 1 . 8}$ \\
\hline
\end{tabular}

level with $10 \%$ non-response rate, the calculated sample was (770).

$2^{\text {nd }}$ phase by assuming change of female adolescent students' knowledge and selfcare behavior about GUTI from $53 \%$ to $80.6 \%{ }^{(8)}$ at $95 \%$ confidence level and power $80 \%$, the calculated sample was (104). Sample size was calculated using OpenEpi software.

Sample technique: (Multistage random sample technique)

First stage: The total number of schools was 15 preparatory schools and three secondary schools in Zagazig city, three preparatory schools and one secondary school were chosen by simple random sampling. 


\begin{tabular}{|c|c|c|}
\hline Items & $\mathbf{N}$ & $\%$ \\
\hline Burning & 462 & 60.0 \\
\hline Frequency & 308 & 40.0 \\
\hline Dysuria & 154 & 20.0 \\
\hline Blood in urine & 23 & 3.0 \\
\hline $\begin{array}{l}\text { Vaginal discharge with } \\
\text { inflammation between } \\
\text { thigh }\end{array}$ & 143 & 18.6 \\
\hline $\begin{array}{l}\text { Vaginal itching after } \\
\text { menses }\end{array}$ & 193 & 25.0 \\
\hline Redness in vulva & 100 & 13.0 \\
\hline History of UTI & 115 & $14.9 \%$ \\
\hline
\end{tabular}

Second stage: Three classes from each school at different educational level(first, second, and third preparatory grades, first, second and third secondary grades)were selected by simple random sampling.

Third stage: Students were selected from classes by simple random sampling with proportional allocation.

Tools of data collection: Included two phases: First phase: Urine samples were collected in sterile containers from all students in the studied groups. Urine examination was done to detect the prevalence of UTI. Urine culture and sensitivity were only done for samples that revealed significant pyuria on urine examination in order to determine the prevalent organisms and their antibiotic susceptibility patterns. Urine samples were cultivated on cystine-lactoseelectrolyte-deficient agar (CLED agar) and MacConkey agar. Only urine cultures with significant bacteriuria (containing more than $10^{5}$ colonies $/ \mathrm{ml}$ of urine using a standard calibrated bacteriological) were presumptively identified by Gram staining and conventional biochemical reactions. Catalase and coagulase tests were used to identify Gram positive cocci while citrate, urease indole, and oxidase tests in addition to cultivation on triple sugar iron were used to identify Gram negative rods.

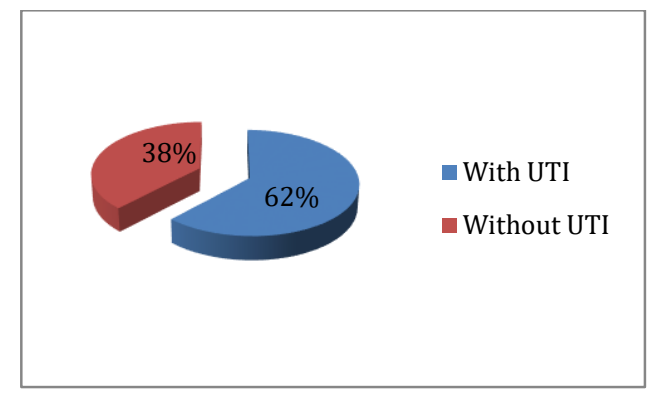

Figure (1): Prevalence of urinary tract infections among adolescent females after urine analysis

Second Phase: An interviewing questionnaire was designed to collect data and composed of four main parts to assess the followings: (1) Socio-demographic characteristics including age, parents' education, occupation, monthly income, number of family members and residence. this part includes (7) questions. (2) Health problems complain included questions about vaginal discharge, vaginal itching, redness of valve, burning sensation during urination, chronic lower abdominal pain and history of UTI includes 7 questions. (3) Students knowledge about genitourinary tract infection was assessed using a 10 items questionnaire including questions on the meaning of GUTI, the causes, the risk factors, the signs and symptoms, the types, the complications. (4) Personal hygiene habitual practices among female students regarding prevention of GUTI: which encompassed 33 questions about the healthy practices related to: Perineal hygiene included questions concerning cleaning perineal area, methods of cleaning, direction of cleaning, dryness of perineal area, using antiseptic solution or talcum powder, removal of pubic hair.

Menstrual hygiene included questions about type of towels used during menstruation, changing of towels, and shower during menses, route of shower, cleaning perineal area during menstruation, using perfumed materials, washing hands. Change underwear and pantyhose every day, if the underwear were all cotton.

Operational design: 
Pilot study: A pilot study was conducted on $10 \%$ of the total studied adolescent female students to evaluate the content and clarity of the tools, as well as to estimate the time needed for data collection. The necessary modifications were performed; the results of pilot study were not included in the study.

Field work: all participants underwent data collection, assessment of knowledge of the students then they underwent health education. By the end of the study, their knowledge was assessed again to evaluate outcome of educational program.

Administrative design: Approval to conduct the research was obtained from an institutional review board (IRB \#5641). Informed consents were obtained from every student including objectives, benefits of the study and confidentiality of the individual data was assured. An official permission was obtained from the director of Zagazig University hospitals to the manager of each school after explaining the aim of the research to get the permission for data collection.

\section{Statistical analysis:}

The data collected were presented in a suitable manner using tables and different types of graphs, and statistically analyzed using the suitable tests throughout Statistical Package of Social Services (SPSS) version 20.0. Result were considered statistically significant when the significant probability was less than $5 \%(\mathrm{p}<0.05)$.

Scoring system for students' knowledge: The female students' knowledge was calculated for each item as follows: Complete and /or correct answer was scored (2 points), Incomplete correct answer was scored (1point) while don't know or wrong answer was scored (zero point).The total score for all questions related to knowledge was 20 point which represents $100 \%$ and categorized into two levels as followings: Satisfactory of the total score $\geq 60 \%$ and Unsatisfactory $<60 \%$.
Scoring system for student Personal hygiene habitual practices questionnaire: Each Personal hygiene practices were scored as one point and each unhygienic practice scored as zero point. For the practice "yes" response scored as one and if response "no" scored as zero. The total score of practices was 43 points, which represents $100 \%$. Final practice assessment score was as hygienic practice $\geq 75 \%$ and unhygienic practice $<75 \%$.

Validity and reliability: The validity of questionnaires and health education messages was evaluated by a panel of experts from Community, Environment and Occupational Medicine department in Zagazig University. The reliability coefficient test (Cronbach's alpha) was = 0.72 .

\section{Results}

Mean age of the studied sample was 14.2 \pm SD $2.1,37.92 \%$ in second preparatory grade. $37.92 \%$ of their mothers completed high education $\& 76 \%$ of their mothers were housewives. $68.8 \%$ of the studied students had enough monthly income. $78.2 \%$ with good housing condition (table $1)$.

About $15 \%$ of the students had medical history for urinary tract infection symptoms. Regarding the present health complaints, $60 \%, 25 \%, 20 \%, 18.6 \%, 13 \%$ of the studied students reported having burning sensation, vaginal itching after menses, dysuria, vaginal discharge, and redness in vulva respectively (table 2). Sixty two of the collected samples revealed urinary tract infections (figure $1)$.

Prevalence of bacteria after urine culture and found that E. coli was $24.75 \%$ the highest prevalence and found about $10 \%$ of samples were sterile (table 3 ).

Regarding antibiotic sensitivity, $13 \%$ of samples were sensitive to ciprofloxacin and $12 \%$ were sensitive to tetracycline and Amikacin (figure 2).

Female adolescent students' knowledge score level improved after the program 
Table (3) Prevalence of isolates in urine samples $(\mathrm{N}=477)$ :

\begin{tabular}{llc}
\hline \multicolumn{1}{c}{ Isolates } & $\%$ \\
\hline 1- & Escherichia coli & 24.75 \\
2- & Proteusspp. & 16.27 \\
3- & Klebsiella spp. & 13.68 \\
4- & Staphylococcus spp. & 11.07 \\
5- Unidentifiable Isolates & and \\
& candida & 10.34 \\
6- & Streptococcus spp. & 8.63 \\
7- & Pseudomonas spp. & 5.26 \\
8- Sterile Sample & 10.0 \\
\hline
\end{tabular}

implementation, in context of meaning of genitourinary tract infection, causes, symptoms and complications ( $\mathrm{p}$ value $<$ 0.001) (table 4).

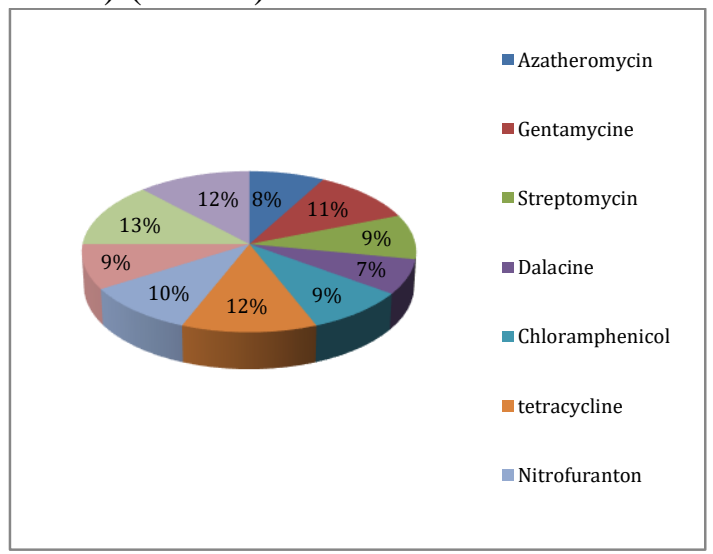

Figure (2): Antibiotic sensitivity of bacteria isolates.

Hygienic practices significantly improved after program implementation regarding clean perineal area, menstrual hygiene and suitability and care of underwear ( $p$ value $<0.001$ ) (table 5).

There is statically significant improvement in post-test regarding health complaints from genitourinary tract as vaginal discharge, vaginal itching, burning sensation and dysuria $(\mathrm{p}=0.002$, $\mathrm{p}=<0.001, \mathrm{p}=<0.001$ and $\mathrm{p}=<0.001$ respectively) (table 6 ).

\section{Discussion}

Genitourinary tract infections are common in female adolescents due to lack of hygiene experience. This is the period of menstruation as well and it is considered new condition in this age, often associated with significant morbidity affecting genital tract. ${ }^{9}$
In the present study, $37.92 \%$ and $35.06 \%$ of students had mothers with high and intermediate education, respectively, and more than two thirds of them their mothers were housewives and had enough monthly income. About $78 \%$ of student females with sanitary housing condition. Fifteen percent of studied group with history of UTI are in agreement with AlKotb et al. ${ }^{8}$ who found that $13 \%$ of their patients had history of GUTI. A similar work in Iran applied on first-grade high school female students reported that $11 \%$ the female students at the age of 15 years had a history of UTI ${ }^{(10)}$.

As regard other symptoms of UTI, $60.0 \%$, $40 \%, 20 \%, 18.6 \%$, and $25 \%$ of students had burning sensation, frequency, dysuria, vaginal discharge and vaginal itching, respectively. These findings were in agreement with Srivastava ${ }^{1}$ who found that $60 \%, 40 \%, 36 \%$ and $32 \%$ of the study participants had burning sensation, frequency, dysuria, vaginal discharge and vaginal itching respectively.

The current result revealed that $62 \%$ of collected samples have UTI these results in agreement with a previous study where the same percentage had positive for UTIs; having not less than $10^{5}$ colony forming units of bacteria per $1 \mathrm{ml}$ of clean voided, mid-stream urine.

In this study, $E$ coli had the highest prevalence $(24.75 \%)$, current results were in the same line with Ojo and Anibijuwon. ${ }^{7}$ The causative E. coli strain often can be found in the woman's faecal flora at the time of a UTI episode. This observation has suggested the 'faecalperineal-urethral' hypothesis for UTI pathogenesis in women, according to which the host's own faecal flora is the immediate external reservoir from which E. coli strains emerge to cause UTI. $^{11}$

An earlier work by Smith et al. ${ }^{12}$ found out that $E$. coli accounts for $32 \%$ of UTI cases. Proteuss pecies with $17.25 \%$ prevalence has a significant association with UTI. On the other hand, 
Table (4): Distribution of female adolescent students' knowledge before and after implementation of the program as regards items related to genitourinary tract infection $(\mathrm{N}=$ 104).

\begin{tabular}{|c|c|c|c|c|c|c|c|c|c|c|}
\hline \multirow{4}{*}{ Items } & \multicolumn{8}{|c|}{ Score of knowledge } & \multirow{4}{*}{$\begin{array}{c}\text { Mc- } \\
\text { Nmar } \\
\text { test }\end{array}$} & \multirow{4}{*}{$P$ value } \\
\hline & \multicolumn{4}{|c|}{ Before } & \multicolumn{4}{|c|}{ After } & & \\
\hline & \multicolumn{2}{|c|}{$\begin{array}{c}\text { Un } \\
\text { Satisfactory }\end{array}$} & \multicolumn{2}{|c|}{ satisfactory } & \multicolumn{2}{|c|}{$\begin{array}{c}\text { Un } \\
\text { Satisfactory }\end{array}$} & \multicolumn{2}{|c|}{ satisfactory } & & \\
\hline & $\mathbf{N}$ & $\%$ & $\mathbf{N}$ & $\%$ & $\mathbf{N}$ & $\%$ & $\mathbf{N}$ & $\%$ & & \\
\hline $\begin{array}{l}\text { Meaning of } \\
\text { GUTI }\end{array}$ & 79 & 75.5 & 25 & 24.5 & 7 & 6.7 & 97 & 93.3 & 64.33 & $<0.001 *$ \\
\hline Causes & 83 & 80.0 & 21 & 20.0 & 47 & 45.0 & 57 & 55.0 & 28.56 & $<0.001 *$ \\
\hline Symptoms & 71 & 68.0 & 33 & 32.0 & 21 & 20.0 & 83 & 80.0 & 42.48 & $<0.001 *$ \\
\hline Complication & 47 & 45.5 & 57 & 55.5 & 15 & 14.5 & 89 & 85.5 & 24.37 & $<0.001 *$ \\
\hline
\end{tabular}

* statistically Significant difference

Table (5): Distribution of female adolescent students as regard personal hygiene practices related tohabits before and after implementation program $(\mathrm{N}=104)$.

\begin{tabular}{|c|c|c|c|c|c|c|c|c|c|c|}
\hline \multirow{4}{*}{ Items } & \multicolumn{8}{|c|}{ Personal hygiene practice } & \multirow{4}{*}{$\begin{array}{c}\text { Mc- } \\
\text { Nmar } \\
\text { test }\end{array}$} & \multirow{4}{*}{$\begin{array}{c}P \\
\text { value }\end{array}$} \\
\hline & \multicolumn{4}{|c|}{ Before } & \multicolumn{4}{|c|}{ After } & & \\
\hline & \multicolumn{2}{|c|}{ Un hygienic } & \multicolumn{2}{|c|}{ Hygienic } & \multicolumn{2}{|c|}{ Un hygienic } & \multicolumn{2}{|c|}{ Hygienic } & & \\
\hline & $\mathbf{N}$ & $\%$ & $\mathbf{N}$ & $\%$ & $\mathbf{N}$ & $\%$ & $\mathbf{N}$ & $\%$ & & \\
\hline $\begin{array}{l}\text { Perineal } \\
\text { hygiene }\end{array}$ & 47 & 45.5 & 57 & $\begin{array}{l}54 . \\
5\end{array}$ & 24 & $\begin{array}{l}23 \\
.4\end{array}$ & 80 & 76.6 & 16.0 & $<0.001$ \\
\hline $\begin{array}{l}\text { Menstrual } \\
\text { hygiene }\end{array}$ & 50 & 48.1 & 54 & $\begin{array}{l}51 . \\
9\end{array}$ & 14 & $\begin{array}{l}13 \\
.5\end{array}$ & 90 & 86.5 & 28.65 & $<0.001$ \\
\hline $\begin{array}{l}\text { Suitability } \\
\text { and care of } \\
\text { underwear }\end{array}$ & 58 & 55.8 & 46 & $\begin{array}{l}44 . \\
2\end{array}$ & 24 & $\begin{array}{l}22 \\
.9\end{array}$ & 70 & 77.1 & 16.96 & $<0.001$ \\
\hline
\end{tabular}

Mars $^{13}$ found that Streptococcus species and Pseudomonas species are the common causative agents of UTIs. Also $10.0 \%$ of the studied samples were sterile may be due to intake of antibiotics or presence of non-conventional organisms as mycobacterium and chlamydia which need specific media for culture.

It was not applicable to take vaginal smears to perform vaginal culture and sensitivity in order to detect the prevalence of infection and organisms because of the culture, tradition, and virginity issues, so diagnosis depended on the present and history of clinical symptoms.

The studied participants showed a significant improvement in the knowledge about meaning of GUTI, causes, symptoms and complications after educational program. Such finding agreed with that of previous studies in Iran and
Bengladish ${ }^{3,7-10}$, and this due to lack of knowledge in pretest and the students were interested in the effective intervention. This is also promising that application of such education can improve hygienic practice and that students are willing to adhere to physician advice.

In the pretest, concerning personal hygiene habitual practices among the students, $45.5 \%, 48.07 \%$, and $55.8 \%$ of them had unhealthy hygienic habitual practices regarding perineal hygiene, menstrual hygiene, and care of underwear, respectively, whereas in the post test, there was a highly significant improvement in these hygiene habitual practices after implementation program. Consistent with previous reports, most girls were using incorrect washing and wiping technique of genitals in addition to incorrect direction; therefore, most had symptomatic GUTI. ${ }^{14}$ This also is 
Table (6): Distribution of studied students according to their genitourinary tract health complains before and after implementing the program $(\mathrm{N}=104)$

\begin{tabular}{|c|c|c|c|c|c|c|}
\hline \multirow{3}{*}{ Items } & \multicolumn{4}{|c|}{ Score of knowledge } & \multirow{3}{*}{$\begin{array}{c}\text { Chi } \\
\text { square }\end{array}$} & \multirow{3}{*}{$\begin{array}{c}P \\
\text { value }\end{array}$} \\
\hline & \multicolumn{2}{|c|}{ Before } & \multicolumn{2}{|c|}{ After } & & \\
\hline & No & $\%$ & No & $\%$ & & \\
\hline $\begin{array}{l}\text { Vaginal } \\
\text { discharge with } \\
\text { inflammation } \\
\text { between } \\
\text { Thigh }\end{array}$ & 19 & 18.6 & 5 & 4.8 & 9.23 & 0.002 \\
\hline $\begin{array}{l}\text { Vaginal itching } \\
\text { after menses }\end{array}$ & 26 & 25.0 & 5 & 4.8 & 16.71 & $<0.001$ \\
\hline $\begin{array}{l}\text { Burning } \\
\text { sensation with } \\
\text { urination }\end{array}$ & 62 & 60.0 & 21 & 20.0 & 33.7 & $<0.001$ \\
\hline Dysuria & 21 & 20.0 & 6 & 5.7 & 9.57 & $<0.001$ \\
\hline
\end{tabular}

considered a strong evidence that the students need only healthy instruction to change practice.

Similarly, Bakr et al. ${ }^{15}$ reported that girls did not perform adequate menstrual hygiene. Poor menstrual hygiene practices present risk factor for genital tract infections as well as UTIs, and health education on this topic is of great significance. Özyazıcıoğlu et al. ${ }^{16}$ found that a significant increase in knowledge and change behavior was observed after the education on menstrual and perineal hygiene and care of underwear.

In the present study, it was found that the studied students complain of the symptoms of GUTI before implementing program had markedly decreased after implementing the program. Moreover, there was statistically significant relation between the symptoms GUTI before and after implementing the program regarding prevention of GUTI. There was clear links between poor menstrual hygiene and health problems such as GUTI. There was a higher risk of infections during menstruation when the cervix opens and creates a pathway for microbes to enter the uterus and pelvic cavity. In scientific terms the $\mathrm{pH}$ in the vagina during this period becomes less acidic and this creates a good environment for yeast infections such as candidiasis. The above is confirmed by previous studies by Sevil ${ }^{6}$ and Thakreet al. ${ }^{17}$ Female adolescent students in this stage need repeated educational content regularly to increase the durability because their knowledge and good practices decrease overtime.

The study had some limitations including lack of vaginal smears examination, limited follow up time and relying on subjective assessment of students without objective assessment by repeating urine cultures.

\section{Conclusion}

Most the studied students have improved their knowledge related to GUTI causes, signs, and symptoms in addition to the adverse effects of GUTI on themselves and on their health. The study findings also reported an improvement in habitual hygiene practices after implementation of the program which lead to reduced complain of symptoms of GUTI regarding studied students.

\section{Recommendation}

Students counseling during periodic medical examination about personal hygiene, and important of menstrual hygiene is recommended. Health education to female students about the danger of unhygienic measures of perianal care related to genitourinary infection. To increase the success of the education, teachers and health officials must collaborate with parents and other 
family members, share information with them and educate the students who are away from their families through a comprehensive health program. Health officials and nurses should be more sensitive to young people and plan trainings related to bathroom hygiene, to be provided in partnership with the school administration.

\section{References:}

1- Srivastava S. Analytical study of urinary tract infection in adolescent girls International Journal of Reproduction, Contraception, Obstetrics and Gynecology, Int J Reprod Contracept Obstet Gynecol. 2018;7(4):13851388.

2- Badran YA, El-Kashef TA, Abdelaziz AS and Ali MM. Impact of genital hygiene and sexual activity on urinary tract infection during pregnancy. UrolAnnals 2015;7(4):478-81.

3- Changizi M., Zadeh DS, Zinat-Motlagh F, Fattahi M., Mahboubi M. Beliefs of Female Teenagers on Prevention of Urinary Tract Infection: Application of Health Belief Model. Journal of Biology and Today's World 2014, 3(10): 223-226.

4- Suryana A, Patria Y and SadjiminT. The risk factors of urinary tract infection among elementary school students inSleman District, Yogyakarta Special Region. Journal of the Medical Sciences (BerkalailmuKedokteran) 2015, 44 (02).

5- Hassan M. Effect of intervention guidelines on self care practices of pregnant women with urinary tract infection. LifeScience Journal 2015, 12(1): 113-124.

6- Sevil S., Kevser O, Aleattin U, Dilek A and Tijen N. An Evaluation of the relationship between genital hygiene practices, genital infection. Gynecology \& Obstetrics 2013 ;3: 187.

7- Ojo OO and Anibijuwon II. Urinary tract infection among female students residing in the campus of the University of Ado Ekiti, Nigeria, African Journal of Microbiology Research $2010 ; 4$ (12):1195-1198.
8- Al- Kotb H, Elbahnasawy HT and El Nagar SA. Prevention for Genitourinary Tract Infection among Female Adolescents Students. Journal of Nursing and Health Science 2016 ;5(4) :12-18.

9- Indhumol T, Pavithran S and George LK. Effectiveness Of Structured Teaching Program On Knowledge Regarding Prevention Of Urinary Tract Infection Among Adolescent Girls.International Journal of Pharma Medicine and Biological Sciences 2014, 3(3):121.

10- Jahanbin I, Heydari N, Ghodsbin F, Sayadi M. The Effect of Peer-Education on UTI-Related Preventive Behavior According to HBM among First-Grade High School Female Students in Shiraz. Journal of health sciences and surveillance system 2014, 3(1): p. 20-26.

11- Moreno E, Andreu A, Pérez T, Sabaté M, Johnson JR, Prats G. Relationship between Escherichia coli strains causing urinary tract infection in women and the dominant faecal flora of the same hosts. Epidemiol Infect. 2006;134(5):1015-1023.

12- Smith PB, Barry AL and Truck M. Laboratory Diagnosis of urinary tract infections. Am. Microbiol.2003: 2: 1-7.

13- Mars PS. Urinary tract infection. Merck manual of diagnosis and therapy. Merck research lab. Railway N.J 2002: 1178411798.

14- Ahmed Sand, Avasarala A. Urinary tract infections (UTI) among adolescent girls in rural Karimnagar District, AP KAP STUDY Indian J Pre Soc Med. 2008 ,39:(1 \& 2).

15- Bakr KK, Dutta A, Swain T and Sahoo S. Menstrual Hygiene Practices, WASH Access and the Risk of Urogenital Infection in Women from Odisha, India PLOS ONE 2015; 10(6): e 0130777.

16- Özyazıcıoğlu N, Ünsal A and Sezgin S. The Effects of Toilet and Genital Hygiene Educationon High SchoolStudents' Behavior, International Journal of Caring Sciences 2011; 4 (3):120-125.

17- Thakre SB. et al. Menstrual hygiene: knowledge and practice among adolescent school girls of Saoner, Nagpur district. J Clin Diagn Res 2011, 5(5): 1027-1033 